\title{
Diagnostic Accuracy in Appendicitis: A Histopathological Study
}

\author{
Sitara A. Sathar T.A. Junaid \\ Department of Pathology, Faculty of Medicine, Kuwait University, Kuwait
}

\section{Key Words}

Appendicitis, diagnostic accuracy $\cdot$ Histopathology

\begin{abstract}
Objective: Although appendicectomy accounts for the highest number of unnecessary surgical procedures, there is little information on the accuracy of the procedure in Kuwait. Therefore, the objective of this study was to determine the accuracy of pre-operative diagnosis of acute appendicitis and the influence of age, gender and surgical personnel on the rate of normal appendicectomy. Materials and Methods: A retrospective histopathological review of specimens involving 'acute appendicitis' in the surgical pathology files of the Mubarak AlKabeer Hospital, Kuwait in 1982-1986 and 1992-1996 was carried out. The diagnostic accuracy (DA) was defined as the proportion of specimens in which an inflamed appendix was confirmed microscopically and the negative appendicectomy rate (NAR) was the proportion of appendices that were microscopically normal. Results: The DA was 80 and $84 \%$ for $1982-1986$ and $1992-$ 1996 , respectively. There was a marked decline in the number of females in the second period from 42 to $30 \%$. Females, who accounted for $36 \%$ of all cases, comprised $61 \%$ of normal appendicectomies with the highest NAR in the 20- to 29-year age group (23.7\%). The NAR decreased in the second period from 18.4 to $12.4 \%$. Conclusion: The results show that the clinical diagnostic
\end{abstract}

accuracy of appendicitis in Mubarak Al-Kabeer Hospital is consistent with reports from several centres. However, auditing with routine histopathological examination is still necessary to improve clinical evaluation, particularly in females, many of whom are still subjected to the risks of unnecessary laparotomy.

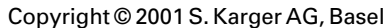

\section{Introduction}

Presumptive diagnosis of acute appendicitis is the commonest cause for laparotomy in North America and Western Europe where appendicitis is common [1]. In these regions there is continued effort to improve the preoperative diagnosis because between 10 and $50 \%$ of appendices removed are histologically normal [2]. Unnecessary appendicectomy carries long-term risks to the patient and improvement in the clinical diagnosis of appendicitis would both lessen the risk of the rare but definite complications (7.7\%) of the procedure and save medical resources [3].

In Kuwait, as in other parts of the Arabian Gulf, laparotomy for presumed appendicitis is rather common. The accuracy of such diagnosis and laparotomies that follow has rarely been studied [4]. As histopathological examination of surgically resected organs or tissue is the accepted yardstick of quality control of surgical practice, the present study is designed to assess the accuracy of pre-

\section{KARGER \\ Fax +4161306 1234 \\ E-Mail karger@karger.ch \\ www.karger.com

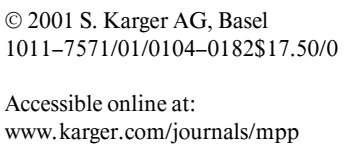

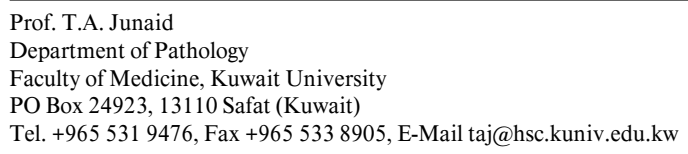


Table 1. Distribution of appendiceal lesions for the period 1982-1986 by histopathological examination

\begin{tabular}{|c|c|c|c|c|c|c|c|c|c|c|c|c|c|}
\hline \multirow[t]{2}{*}{$\begin{array}{l}\text { Age } \\
\text { years }\end{array}$} & \multicolumn{2}{|c|}{$\begin{array}{l}\text { Acute appendicitis/ } \\
\text { periappendicitis }\end{array}$} & \multicolumn{2}{|c|}{ Other lesions } & \multicolumn{2}{|c|}{ Normal } & \multicolumn{3}{|c|}{ Total } & \multicolumn{2}{|c|}{ DA, $\%$} & \multicolumn{2}{|c|}{ NAR, \% } \\
\hline & $\mathrm{F}$ & M & $\mathrm{F}$ & M & $\mathrm{F}$ & M & F & M & $\mathrm{F}+\mathrm{M}$ & $\mathrm{F}$ & M & $\mathrm{F}$ & M \\
\hline $0-9$ & 34 & 34 & 0 & 0 & 12 & 7 & 46 & 41 & 87 & 73.9 & 82.9 & 26.1 & 17.1 \\
\hline $10-19$ & 372 & 498 & 0 & 5 & 142 & 64 & 514 & 567 & 1,081 & 72.3 & 87.8 & 27.6 & 11.3 \\
\hline $20-29$ & 218 & 401 & 3 & 9 & 106 & 51 & 327 & 461 & 788 & 66.7 & 87 & 32.4 & 11.1 \\
\hline $30-39$ & 131 & 282 & 1 & 7 & 49 & 27 & 181 & 316 & 497 & 72.4 & 89.2 & 27.1 & 8.5 \\
\hline $40-49$ & 33 & 116 & 2 & 5 & 15 & 10 & 50 & 131 & 181 & 66 & 88.5 & 30 & 7.6 \\
\hline $50-59$ & 8 & 27 & 0 & 0 & 3 & 5 & 11 & 32 & 43 & 72.7 & 84.4 & 27.3 & 15.6 \\
\hline$>60$ & 5 & 8 & 0 & 0 & 4 & 2 & 9 & 10 & 19 & 55.6 & 80 & 44.4 & 20 \\
\hline Total & 801 & 1,366 & 6 & 26 & 331 & 166 & 1,138 & 1,558 & 2,696 & Mean 68.5 & 85.7 & 30.7 & 13.0 \\
\hline
\end{tabular}

$\mathrm{F}=$ Female; $\mathrm{M}=$ male. Combined $(\mathrm{F}+\mathrm{M}) \mathrm{DA} 2,167 / 2,696=80.4 \% ;$ combined $(\mathrm{F}+\mathrm{M}) \mathrm{NAR}$ 497/2,696 = 18.4\%.

operative diagnosis of acute appendicitis over two different 5-year periods at the Mubarak Al-Kabeer Hospital, Kuwait. The findings would be compared to similar studies reported from elsewhere and would be related to the age and sex of the patients, and the effects, if any, the change in surgical personnel between the two periods had on the accuracy of surgical diagnosis.

\section{Materials and Methods}

All cases registered as appendices in the surgical pathology files of the Mubarak Al-Kabeer Hospital, Kuwait between January 1, 1982 and December 31, 1986 (pre-invasion) and January 1, 1992 and December 31, 1996 (post-invasion) were retrieved. Cases submitted as incidental appendicectomies were excluded from the study. During the periods of study, a longitudinal section from the distal third including the tip of the formalin-fixed appendix and one transverse section each from the proximal and middle portions were routinely processed in paraffin and stained with haematoxylin and eosin for microscopic examination. Histopathological slides of registered specimens were reviewed and categorized as acute appendicitis, periappendicitis, or other specified lesions such as schistosomiasis, specific tumours, or normal. To compensate for the lack of standardization inherent in retrospective studies, a rather liberal definition of acute appendicitis that encompassed neutrophilic infiltration of the mucosa, lamina propria, muscularis and/or serosa of the appendix was used. Data on age, sex and the pre-operative clinical diagnosis were obtained from the accompanying laboratory request forms, or patients' files where available.

The diagnostic accuracy (DA) was defined as the proportion of specimens in which microscopy showed acute appendicitis. The negative appendicectomy rate (NAR) was the proportion of operated patients in whom histological examination did not show inflammatory changes as defined above. Chi square test was used for statistical analysis. A $p$ value of $<0.05$ was accepted as significant.

\section{Results}

In the pre-invasion period (1982-1986) data on sex and age were obtainable on 2,696 out of $2,883(93.5 \%)$ persons who had their appendices removed. Of these, $1,558(57.8 \%)$ were males and $1,138(42.2 \%)$ females. The mean age of the males was 25 years and the females 21 years. The DA for both sexes together was $80.4 \%$, for males and females alone $85.7 \%$ and $68.5 \%$, respectively. The corresponding NAR values are 18.4, 13.0 and $30.7 \%$ (table 1).

The DA and NAR for the two sexes showed significant differences $(p<0.001)$ in the first four decades of life when the largest number of patients had their appendices removed. The DA was lowest for females aged 20-29 years when nearly 1 of 3 appendices were histologically normal (NAR 32.4\%).

Data on sex and age were obtained in 2,876 subjects; between 1992 and 1996 (post-invasion) 2,002 (69.6\%) men and $874(30.4 \%)$ women had appendicectomies, with mean ages of 25 and 23 years, respectively. As shown in table 2, DA for both sexes was 84.3, 87.0 for men, and $78.5 \%$ for women. The corresponding NARs were 12.3 , 7.4 and $16.8 \%$. As in the earlier period the lowest DA (70.7\%) was obtained in females in the 20- to 29-year age group where also the highest NAR (23.7\%) was found. The comparative data for both periods is shown in table 3. In the post-invasion period, the highest number of appendicectomies was performed in the 20- to 29-year age group rather than the 10- to 19-year age group of the preinvasion period (table 1, 2). 
Table 2. Distribution of appendiceal lesions for the period 1992-1996 by histopathological examination

\begin{tabular}{|c|c|c|c|c|c|c|c|c|c|c|c|c|c|}
\hline \multirow[t]{2}{*}{$\begin{array}{l}\text { Age } \\
\text { years }\end{array}$} & \multicolumn{2}{|c|}{$\begin{array}{l}\text { Acute appendicitis/ } \\
\text { periappendicitis }\end{array}$} & \multicolumn{2}{|c|}{ Other lesions } & \multicolumn{2}{|c|}{ Normal } & \multicolumn{3}{|c|}{ Total } & \multicolumn{2}{|c|}{ DA, $\%$} & \multicolumn{2}{|c|}{ NAR, \% } \\
\hline & F & M & $\mathrm{F}$ & M & $\mathrm{F}$ & M & $\mathrm{F}$ & M & $\mathrm{F}+\mathrm{M}$ & F & M & $\mathrm{F}$ & M \\
\hline 0-9 & 58 & 94 & 1 & 1 & 14 & 14 & 73 & 109 & 182 & 79.4 & 86.2 & 19.2 & 12.8 \\
\hline $10-19$ & 213 & 489 & 7 & 8 & 77 & 54 & 297 & 551 & 848 & 71.7 & 88.7 & 25.9 & 9.8 \\
\hline $20-29$ & 176 & 579 & 14 & 16 & 59 & 54 & 249 & 649 & 898 & 70.7 & 89.2 & 23.7 & 8.3 \\
\hline $30-39$ & 138 & 439 & 4 & 16 & 30 & 27 & 172 & 482 & 654 & 80.2 & 91.1 & 17.4 & 5.6 \\
\hline $40-49$ & 51 & 126 & 8 & 13 & 4 & 17 & 63 & 156 & 219 & 81 & 80.8 & 6.4 & 10.9 \\
\hline $50-59$ & 8 & 35 & 1 & 6 & 3 & 2 & 12 & 43 & 55 & 66.7 & 81.4 & 25 & 4.7 \\
\hline$>60$ & 8 & 11 & 0 & 1 & 0 & 0 & 8 & 12 & 20 & 100 & 91.7 & 0 & 0 \\
\hline Total & 652 & 1,773 & 35 & 61 & 187 & 168 & 874 & 2,002 & 2,876 & Mean 78.5 & 87.0 & 16.8 & 7.4 \\
\hline
\end{tabular}

$\mathrm{F}=$ Female; $\mathrm{M}=$ male. Combined $(\mathrm{F}+\mathrm{M}) \mathrm{DA} 2,425 / 2,876=84.3 \% ;$ combined $(\mathrm{F}+\mathrm{M}) \mathrm{NAR} 355 / 2,876=12.3 \%$

Table 3. Comparative DA and NAR in both study periods

\begin{tabular}{lcc}
\hline & $1982-1986$ & $1992-1996$ \\
\hline Number & & \\
Females & $1,138(42.2 \%)$ & $874(30.4 \%)$ \\
Males & $1,558(57.8 \%)$ & $2,002(69.6 \%)$ \\
Total & $2,696(100 \%)$ & $2,872(100 \%)$ \\
\hline DA, \% & \\
Females & 68.5 & 78.5 \\
Males & 85.7 & 87.0 \\
Overall & 80.4 & 84.3 \\
\hline NAR, \% & & \\
Females & 30.7 & 16.8 \\
Males & 13.0 & 7.4 \\
Overall & 18.4 & 12.3 \\
\hline
\end{tabular}

DA $1982-1986$ vs. $1992-1996, \mathrm{p}<0.001$; NAR 1982-1986 vs. 1992-1996, $\mathrm{p}<0.0001$.

For both periods the DA was lower in women than men (1982-1986: 68.5 vs. 85.7\%, $\mathrm{p}<0.0001 ; 1992-1996$ : 78.5 vs. $87.0 \%, \mathrm{p}<0.0001)$. Correspondingly, the NAR was higher in women than men (1982-1986: 30.7 vs. $13.0 \%, \mathrm{p}<0.0001 ; 1992-1996$ : 16.8 vs. $7.4 \%$, p < $0.0001)$. There was also a significant difference in the overall DA between the two periods ( 80.4 vs. $84.3 \%$; $p<$ $0.001)$ and between females (68.5 vs. $78.5 \%$; p < 0.05 ). However, the DA in males showed no significant difference $(p=0.4779)$ between the pre- and post-invasion periods.
Between 1982 and 1986, 32 patients ( 6 females and 26 males, $1.2 \%$ ) had other lesions besides acute appendicitis. These were largely fibrotic appendices and parasitic lesions ( 4 schistosomiasis and 1 enterobiasis). There were 3 appendices with carcinoid tumours. Between 1992 and 1996, 96 patients (35 females and 61 males, 3.33\%) had other lesions. Twenty-four of these had schistosomiasis, half coexisting with acute inflammation. Incidentally, all patients with appendiceal schistosomiasis were Egyptian males. There were 5 cases of appendiceal carcinoid, 1 of which coexisted with acute appendicitis; 1 carcinoid had infiltrated into the serosa. In 40 patients the appendix was fibrosed. Other findings were enterobiasis in 5 young patients and necrosis of the appendiceal fat, Crohn's disease, adenocarcinoma, appendiceal neuroma and acute oophoritis as solitary cases. In 6 young women, benign physiological cysts of ovaries were submitted along with normal appendices. There were unexplained granulomatous serosal lesions in 6 cases.

\section{Discussion}

The Mubarak Al-Kabeer Hospital is a community hospital affiliated to the Faculty of Medicine, Kuwait University, Kuwait. It was opened in 1981, and between then and the Iraqi invasion on August 2, 1990 consultant surgical services were provided by staff members of the faculty of medicine, mostly Swedes. Between 1992 and 1996 the consultant surgical staff had been replaced by Kuwaitis and other Arabs with British and American training. The DAs and NARs obtained for both periods compare fa- 
vourably with each other and also with those reported in the literature [5]. It is therefore probably correct to assume that in regard to the clinical diagnosis of acute appendicitis, the change in the surgical teams has had no deleterious effect. In fact the overall DA in the second period of the study was higher than in the first period, but the proportion of females was lower and this may explain the higher DA as experiences from most centers have shown that unnecessary appendicectomies are most likely to be performed in young women during the early reproductive period [6]. The lack of significance in the DAs in males in the two periods also lends support to this assertion. The much lower representation of females in the post-invasion period reflects legislation that initially prohibited a large proportion of the migrant workers in Kuwait from bringing in their families soon after liberation of the country. This prohibition also accounts for the shifting of the peak period of appendicectomies from the second to the third decade since wives and children were kept way.

It has been suggested that routine histopathological examination of appendicectomy specimens is unnecessary and a waste of diminishing health care resources [7]. The suggestion has evoked much discussion in the literature [8]. Findings from the present study confirm that between one fifth to a quarter of patients, particularly young females, are still subjected to unnecessary laparotomy and appendicectomies with the attendant risks. Additionally $1-5 \%$ of appendectomy specimens yielded unexpected findings that include carcinoid tumours, carcinoma, Crohn's disease, and schistosomiasis among others. These would be missed without histological examination of removed appendices [9]. Although these missed lesions most often do not influence management or outcome of the appendicectomy, they occasionally affect therapeutic options as they did in the present study where follow-up right hemicolectomy was performed for an adenocarcinoma. The relatively high prevalence of incidental appendiceal schistosomiasis provides further support for the role of migration on disease patterns as Palestinians who left Kuwait after liberation were largely replaced by Egyptians who brought their diseases into the country. However, the exact contribution of schistosomiasis to symptoms of acute appendicitis in endemic areas remains unsettled. This is because schistosomiasis in the appendix is most often seen as calcified ova or fibrosed granuloma which are largely interpreted as 'incidental findings' $[10,11]$.

The rather low DA of acute appendicitis continues to be accepted because of the attitude that early exploration is justifiable in suspected cases to prevent progression to perforation. A perforated appendix has always been thought to have dire consequences in both sexes and especially in young females because of the proximity of the fallopian tubes and ovaries, infections of which may result in future sterility. For these and other reasons, acute appendicitis remains the diagnosis with probably the highest rate of unnecessary surgery. However, the unacceptably high NAR has resulted in several studies being undertaken to improve the diagnostic accuracy. Such studies have evaluated laboratory tests, clinical observation scoring systems, peritoneal cytology, computer-aided diagnosis, ultrasonography and computed tomography. The values of the various tests and examinations have been the subject of recent reviews $[6,12,13]$.

In addition the doctrine of early operation at the expense of DA has been challenged as there is no firm evidence establishing a perforated appendix as a cause of infertility in women [14]. In a recent study of fertility patterns in 9,840 Swedish women aged under 15 years when they had their appendices removed and 47,590 agematched controls from the general population, Andersson et al. [14] found no adverse effects on fertility in women with a history of perforated appendix. They therefore saw no justification for the acceptance of the very high NAR on the grounds of prevention of infertility. This and other studies argue for a re-examination of the prevailing 'operate when in doubt' teaching and suggest the need to adopt a more cautionary approach to the clinical management of suspected acute appendicitis, especially in young women [15]. Our findings of an unacceptably high NAR support the cautionary approach. Furthermore, we would still advocate mandatory histopathological examinations of all appendicectomy specimens as this remains the definitive quality assurance tool of surgical practice. Besides, histological examination would be indispensable in the evaluation of new diagnostic aids introduced to improve clinical DA.

Efforts to improve DA in appendicitis have not been limited to clinical diagnosis alone. The validity of the morphological criterion of 'polymorphs in the muscularis' has been questioned. Wang and his colleagues [16] reported similar cytokine expressions in acutely inflamed and histologically normal appendices removed surgically, and interpreted their findings as clear evidence of an inflammatory response in the latter specimens. In another study, Ring-Mrozik and his colleagues called for a redefinition of negative appendicectomy when they observed that more than two out of three patients with histologically normal appendices showed flattening of the appendiceal mucosal surface epithelium as did those with acute 
inflammation [17]. These challenges to the accepted definition of acute inflammation need to be studied further but are unlikely to replace the time-honoured 'neutrophilic infiltration' yardstick in the foreseeable future for at least two reasons. Firstly, handling of the appendix at laparotomy might explain or contribute to increased cytokine expressions in Wang's cases, and secondly flattening of the appendiceal mucosal surface epithelium often results from hernial obstruction or presence of faecoliths which, while possibly contributing to the subsequent events in acute appendicitis, are not always associated with neutrophilic infiltration [18].

Inherent to all retrospective studies such as the one reported here is the lack of standardization of methodology. Ideally the entire appendix should be submitted for adequate assessment of inflammatory changes since acute inflammation in the very early stage may only involve a segment of the appendix. Therefore, while not entirely satisfactory, the acceptance of neutrophilic infiltration of all or any layer of the appendiceal wall as acute appendicitis should have compensated somewhat for the short-comings in the study.

\section{Conclusion}

The results indicate that the DA was lower in women than men and conversely that the NAR was higher in women than men during the periods under study. These results are consistent with reports from several centers. However, auditing with routine histopathological examinations is still necessary, particularly in females.

\section{References}

1 Andersson RE, Hugander A, Thulin AJG: Diagnostic accuracy and perforation rate in appendicitis: Association with age and sex of the patient with appendectomy rate. Eur J Surg 1992;158:37-41.

2 Deutsch AA, Shani N, Reiss R: Are some appendectomies unnecessary? An analysis of 319 white appendices. J R Coll Surg Edinb 1983;28:35-40.

3 Baigrie RJ, Dehn TC, Fowler SM, Dunn DC: Analysis of 8,651 appendectomies in England and Wales during 1992. Br J Surg 1995;82: 933.

4 Babekir R, Devi N: Analysis of the pathology of 405 appendices. East Afr Med J 1990;67:599_ 602.

5 Chang AR: An analysis of the pathology of 3,003 appendices. Aust NZ J Surg 1981;51: 169-178.

6 Calder JD, Gajraj H: Recent advances in the diagnosis and treatment of acute appendicitis. Br J Hosp Med 1995;54:129-133.
7 Brooks SG, Hughes RG: Selective histopathology for appendix specimens. Lancet 1987; ii: 1456 .

8 Wright DH: Selective histopathology of appendicectomy specimens. Lancet 1988;i:110-111.

9 Chan W, Fu KH: Value of routine histopathological examination of appendices in Hong Kong. J Clin Pathol 1987;40:429-433.

10 Satti MB, Tamini DM, Sohaibani MA, Quorain AA: Appendicular schistosomiasis: A cause of clinical acute appendicitis? J Clin $\mathrm{Pa}$ thol 1987;40:424-428.

11 Adebamowo CA, Akang EE, Ladipo JK, Ajao OG: Schistosomiasis of the appendix. Br J Surg 1991;78:1219-1221.

12 Eriksson S: Acute appendicitis: Ways to improve diagnostic accuracy. Eur J Surg 1996; 162:435-442.

13 Garcia Pena BM, Mandl KD, Kraus SJ, Fischer AC, Fleisher GR, Lund DP, Taylor GA: Ultrasonography and limited computed tomography and the diagnosis and management of appendicitis in children. JAMA 1999;282: 1041-1046.
14 Andersson R, Lambe M, Bergstrom R: Fertility patterns after appendectomy: Historical cohort study. BMJ 1999;318:963-967.

15 Urbach DR, Cohen MM: Is perforation of the appendix a risk factor for tubal infertility and ectopic pregnancy? An appraisal of the evidence. Can J Surg 1999;42:101-108.

16 Wang Y, Reen DJ, Puri P: Is a histologically normal appendix following emergency appendicectomy always normal? Lancet 1996;347: 1076-1079.

17 Ring-Mrozik E, Hecker WC, Wiebecke B, Hansmann A, Trammer A: New morphological findings in so-called negative appendectomies. Eur J Pediatr Surg 1993;3:79-82.

18 Andreou P, Blain S, Du Boulay CE: A histopathological study of the appendix at autopsy and after surgical resection. Histopathology 1990;17:427-431. 